\title{
Mit beiden Beinen in den Wolken
}

Am Anfang war die Skepsis groß. Kann das funktionieren? IT-Anwendungen dezentral in der "Cloud“? Die schlechten Erfahrungen, die einige Unternehmen mit dem Application Service Providing (ASP) gemacht hatten, ließen viele zögern. Hinzu kamen Bedenken bezüglich Compliance- und Sicherheitsanforderungen.

Inzwischen ist die Nutzung des sogenannten Cloud Computings nicht nur Realität, sondern Normalität geworden. Während der Endverbraucher meist Public Clouds nutzt, sind im Unternehmensumfeld für viele Anwendungen Private Clouds im Einsatz. Vorteile von Cloud Computing und

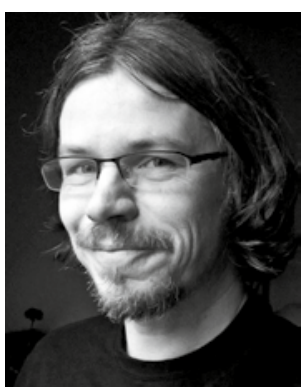

Peter Pagel

Chefredakteur Vor-Ort-Lösungen sollen dabei verbunden werden. Also hohe Flexibilität und Skalierbarkeit bei gleichzeitig maximaler Transparenz und Sicherheit.

Um Compliance-Anforderungen Genüge zu tun, bieten Anbieter Verträge, die sicherstellen, dass sich alle von einem Unternehmen genutzten Server beispielsweise innerhalb der Europäischen Union befinden. So kommt es, dass man heute mit beiden Beinen in den Wolken stehen und dennoch ein bodenständiger Mensch sein kann.

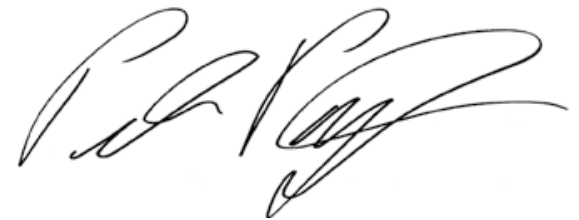

Peter Pagel 